\title{
AB Initio Prediction of Stable Confomeric Polymorphs of Benzocaine Molecule- a Local Anaesthatic Molecule
}

\author{
Pallipurath Veleelath Nidhin, ${ }^{1}$ Arputharaj David Stephen ${ }^{2, *}$ \\ and Charles Selvaraj Arun Paul ${ }^{3}$ \\ ${ }^{1}$ Department of Physics, Sri Shakthi Institute of Engineering and Technology, Coimbatore, India 641062 \\ 2*Assistant Professor of Physics, Department of Physics, Sri Shakthi Institute of Engineering and Technology, Coimbatore, \\ India 641062, Telephone: +91995227392 \\ ${ }^{3}$ Department of Science and Humanities, Sri Krishna Institute of Engineering and Technology, Coimbatore, India-641008 \\ *Corresponding author: E-mail: davidstephen_dav@yahoo.co.in
}

Received: 21-02-2017

\begin{abstract}
An ab initio methodology to predict the crystal structures of thermodynamically stable polymorphs of benzocaine within the least energy region of energy landscape by analyzing the local minima from the initial gas phase optimization initiated through the flexible torsion using MP2/6-31G(d,p) method. The global search for the hypothetical dense packing for the structures within the energy penalty region of the local minima have revealed the possible stable conformers under a repulsion alone potential field. The generated hypothetical dense packings from the global search were selected for lattice minimization using the repulsion - dispersion potential field to authenticate the stability. The stability and the characteristics of the generated structures were analyzed from the comparative hydrogen bond analysis and second derivative properties with the known experimental polymorphs. The morphological studies of the global minima of benzocaine molecule from the valid lattice energy landscape was studied in detail to find the morphological important lattice.
\end{abstract}

Keywords: Polymorphism, Ab initio crystal structure prediction, PES scan, Lattice minimization, 2D Finger print plot, Morphology.

\section{Introduction}

Polymorphism is the ability of a flexible molecule to crystallize in different crystal lattice. As the physiochemical properties of the molecule depends on the crystalline parameters of a molecule, the prediction of different polymorphic structures of a molecule in a crystal phase gains its importance. ${ }^{1}$ Effect of polymorphs may alter the pharmaceutical nature of flexible drug molecules which indeed exposed the search of polymorphs as commercially and academically vital methodology. As the experimental methods to predict, the polymorphs have been considered to be tough to analyse, theoretical ab initio prediction methodology paved the way in easy procedure with more accuracy. Recent reports have been justified the accuracy of Ab initio methodology in predicting the polymorphs of molecular solids. ${ }^{2}$

The prior aim of the current research was to analyze the possible conformeric polymorphs of a local anesthetic molecule of Benzocaine. The reported analysis of the flexible benzocaine with a ester group attached to the aromatic ring, and the amino group attached in the para position to the ester group revealed the presence of three polymorphic forms. The reports suggested that the structures were found to be stabilized through the hydrogen bond interaction between the carbonyl and amino group. The polymorphism exhibited by benzocaine showed the three forms, mainly Form I, Form II and Form III in crystal structure database. The needle like morphological crystals of Form I showed the deviation of the terminal ethyl and carbonyl functional groups from the plane of the phenyl ring, which have justified as the conformational changes in the alkyl ring , thereby increasing the possibility of existence of conformational polymorphism. The Form II crystals are found to be in orthorhombic morphology implementing the $\mathrm{P} 2_{1} / \mathrm{c}$ space group. The low temperature phase transition of form II molecule resulted the forma- 
tion of a twinned monoclinic structure with space group $\mathrm{P} 112_{1}$. The structures were found to be stabilized by the interaction through carbonyl and amine functional groups of the molecule. ${ }^{3,45}$ As the possibility of conformational polymorphism prevailed in the molecules with stability achieved from the position of terminal carbonyl and amine group, ab initio prediction methodology can be initialized for accurate prediction.

\section{Computational Methodology}

The prior aim of the research was the identification of local minima, for the possible crystal structures of the concerned parent molecule which may exhibit conformational polymorphisms. A potential energy surface scan with MP2 level theory using polarized basis set through the selected flexible torsion have been executed. As the central aromatic ring was found to be rigid with $\pi-\pi$ interactions, the terminal torsions $\mathrm{C}(7)-\mathrm{C}(6)-\mathrm{C}(16)-$ $\mathrm{O}(1)$ and $\mathrm{C}(17)-\mathrm{O}(2)-\mathrm{C}(16)-\mathrm{C}(6)$ were taken as $\theta_{1}$ and $\theta_{2}$ (Fig. 1) to execute the Potential Energy Surface scan. Accuracy of the $a b$ initio prediction methodology in identifying the stable polymorphs which satisfies the principle relation of

$$
\mathrm{E}_{\text {total }}=\mathrm{U}_{\text {lattice }}+\Delta \mathrm{E}_{\text {intra }}
$$

solely depends on the exhibition of the local minima associated with the flexible benzocaine molecule. The conformers at local minima and the those which are likely to overcome the energy penalty raised from the torsion distortions are validated by analyzing the energy associated with the distorted conformers.

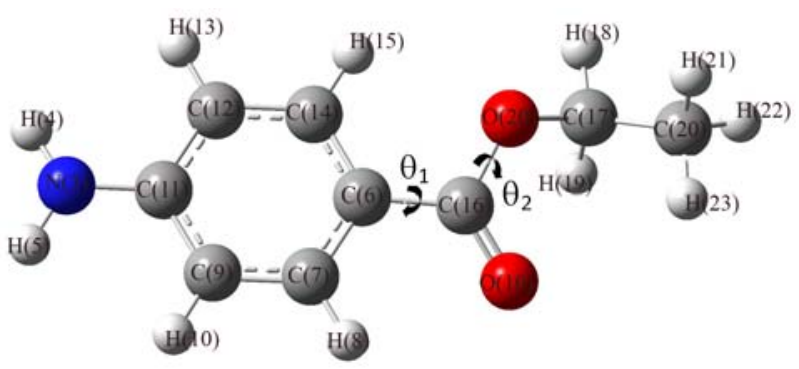

Fig. 1. Benzocaine molecule with selected flexible torsion

The PES scan executed through the flexible torsions $\left(\theta_{1}\right.$ and $\left.\theta_{2}\right)$ commence the partial gas phase optimizations of each step ranging from $-180^{\circ}$ to $180^{\circ}$ of the flexible torsions through MP2 level 6-31G(d,p) basis set using the Gaussian 09 package. ${ }^{6}$ The promising stable conformers are selected for lattice minimization from the troughs of the plot generated using the torsion angles and corresponding energy of each conformers. (Fig. 2), remaining structures were discarded as they were improbable to overthrown the energy penalty of distortion to achieve local minimum.

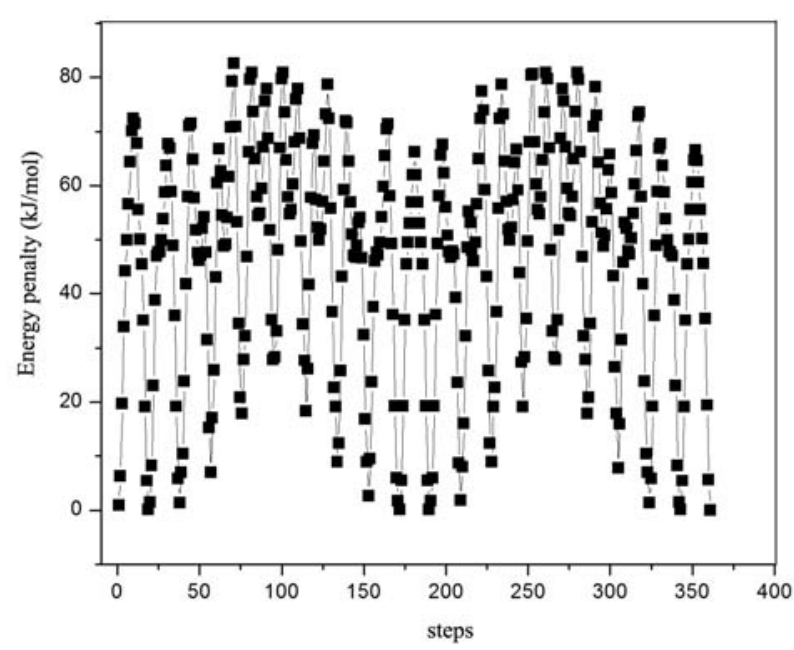

Fig. 2. 2D PES scan plot of the benzocaine molecule with energy penalty associated with each step

The selected within the range of $\sim 5 \mathrm{KJ} / \mathrm{mol}$ of energy penalty of torsion angle distortions with respect to the local minimum were selected and subjected for global search.

\section{1. Global Search}

The global search for the plausible conformers of the benzocaine molecule was executed using the MOLPAK $^{7}$ algorithm to generate the candidate structure in the space group where it belongs; within the most common space groups occurred in the Cambridge structural database (CSD) with the minimum volume of the unit cell. ${ }^{8}$ The MOLPAK global search investigates the unique orientations of the central molecule and constructs approximate coordination patterns of the concerned molecule. Global search algorithm was designed to search for the densest packing patterns of the minimum volume for molecules with fixed conformers. The algorithm initiates the search for the possible dense crystal packings encountering in the common space groups of $\mathrm{P} 1, \mathrm{P}-1$, $\mathrm{P} 2$, Pm, Pc, P2 $1, \mathrm{P} 2 / \mathrm{c}, \mathrm{P} 2_{1} / \mathrm{m}, \mathrm{P} 2 / \mathrm{m}, \mathrm{P} 2_{1} / \mathrm{c}, \mathrm{Cc}, \mathrm{C} 2, \mathrm{C} 2 / \mathrm{c}$, Pnn2, Pba2, Pnc2, P22 , Pmn2 ${ }_{1}, \mathrm{Pma} 2, \mathrm{P} 2{ }_{1} 2_{1} 2_{1}, \mathrm{P} 2{ }_{1} 2{ }_{1}$, $\mathrm{Pca}_{1}, \mathrm{Pna} 2_{1}$ Pnma and Pbca from the 3D orientation and repetition of the central molecule in $10^{\circ}$ steps, ranging from $-90^{\circ}$ to $+90^{\circ}$ specified by the Eulerian angles in a 3Dimensional grid. Each orientations satisfying the threshold interaction with neighboring unit cells have been subjected for the $\mathrm{PMIN}^{9}$ using the repulsion alone UMD potential ${ }^{10}$ to create a possible crystal phase with minimum cell volume initiated through a DFT level theory $^{11}$ using becke 3-Parameter exchange basis set (B3LYP) operation. ${ }^{12}$ The 500 hypothetical crystal structures of benzocaine for each space groups, generated with dense packing were ranked on the basis of minimum cell volume were subjected to the lattice minimization implementing the repulsion dispersion potential field of form 2 


$$
\begin{gathered}
U=\sum_{\mathrm{i} \epsilon 1 \mathrm{ke} 2}\left[\left(\mathrm{~A}_{\mathrm{ii}} \mathrm{A}_{\mathrm{kk}}\right)^{1 / 2}\right] \exp \left[-\left(\mathrm{B}_{\mathrm{ii}}+\right.\right. \\
\left.\left.\mathrm{B}_{\mathrm{kk}}\right) \mathrm{R}_{\mathrm{ik}} / 2\right]-\left(\mathrm{C}_{\mathrm{ii}} \mathrm{C}_{\mathrm{kk}}\right)^{1 / 2} / \mathrm{R}_{\mathrm{ik}}^{6}
\end{gathered}
$$

\section{2. DMACRYS Minimization}

Lattice minimization of the generated conformers from the MOLPAK global search were executed by implementing the repulsion dispersion potential using the DMACRYS ${ }^{13}$ algorithm, rectifying the effect of repulsion alone UMD potential in the global search. The minimization was initiated with the candidate structure with space group constraints by analyzing the distributed multipole associated with the system through GDMA ${ }^{14}$ algorithm. The algorithm imposes the FIT potential field of the form (2), parameterized by Williams and $\operatorname{Cox}^{15}$ with additional terms for the hydrogen atoms bound to nitrogen later fitted by Coombes et al. ${ }^{16}$ The promising densest hypothetical benzocaine crystals at $0 \mathrm{~K}$ were refined from the analysis of the Ewald summed charge-charge, charge-dipole, dipole-dipole interactions of the molecules. The second derivative properties of the rigid conformers were calculated by the algorithm to justify the thermodynamic and mechanical stability of the benzocaine polymorphs. The stability of the lattice minimized benzocaine conformers were authenticated from the born criterion ${ }^{17}$ achieved by the conformers and those conformers which get minimized with negative eigen values where re minimized by removing the negative representation of the symmetric constraints.

The candidate structures preferred from the lattice minimizations were compared with the experimental polymorphs of benzocaine through COMPACK ${ }^{18}$ comparison. The algorithm determines the similarity of the optimized structures with experimental from the least RMS deviation in the crystal packing. The optimized rigid conformers of benzocaine with RMSD less than 0.4 with 20 molecules in common for a coordination sphere of 20 molecules within $40 \%$ of tolerance were selected as duplicates and discarded from the studies. The unique structures of benzocaine with valid minimization were ranked on the basis of the energy (Table 1) associated and selected to generate the energy landscape. ${ }^{19}$

\section{Results and Discussion}

\section{1. Energy Landscape Validation}

The generated energy landscape (Fig. 4) was authenticated by exploiting the presence of experimental known polymorphs of benzocaine molecule in the gene-

\begin{tabular}{|c|c|c|c|c|c|c|c|c|c|}
\hline$\overline{\text { Structure }}$ & $\begin{array}{c}\text { es } \begin{array}{c}E_{\text {total }} \\
(\mathbf{K J} / \mathbf{m o l})\end{array}\end{array}$ & Density & $\begin{array}{c}\text { Space } \\
\text { Group }\end{array}$ & $a(\AA)$ & $b(\AA)$ & $c(\AA)$ & $\alpha\left(^{\circ}\right)$ & $\beta\left(^{\circ}\right)$ & $\gamma\left({ }^{\circ}\right)$ \\
\hline benz1 & -99.676 & 1.191 & $\mathrm{P} 2_{1} 2_{1} 2_{1}$ & 4.713 & 8.363 & 23.373 & 90.00 & 90.00 & 90.00 \\
\hline benz2 & -98.293 & 1.172 & $\mathrm{P} 2{ }_{1} / \mathrm{c}$ & 8.235 & 6.069 & 18.746 & 90.00 & 92.45 & 90.00 \\
\hline benz4 & -98.278 & 1.172 & $\mathrm{P} 2 / 1 \mathrm{c}$ & 8.235 & 6.069 & 18.747 & 90.00 & 92.52 & 90.00 \\
\hline benz5 & -99.710 & 1.191 & $\mathrm{P} 22_{1} 2_{1}$ & 8.364 & 4.706 & 23.397 & 90.00 & 90.00 & 90.00 \\
\hline str 1 & -122.126 & 1.263 & $\mathrm{P} 2{ }_{1} / \mathrm{c}$ & 9.052 & 6.630 & 15.550 & 90.00 & 111.46 & 90.00 \\
\hline str 2 & -121.348 & 1.258 & $\mathrm{P} 2_{1}$ & 9.053 & 14.583 & 6.607 & 90.00 & 90.64 & 90.00 \\
\hline str 3 & -121.275 & 1.260 & $\mathrm{P} 2_{1}$ & 9.053 & 14.560 & 6.609 & 90.00 & 89.93 & 90.00 \\
\hline $\operatorname{str} 4$ & -120.007 & 1.280 & $\mathrm{P} 1$ & 6.785 & 12.070 & 16.185 & 26.09 & 130.59 & 131.89 \\
\hline str 5 & -119.749 & 1.254 & $\mathrm{Cc}$ & 10.731 & 12.817 & 16.555 & 90.00 & 157.40 & 90.00 \\
\hline str 6 & -119.100 & 1.238 & P-1 & 6.905 & 9.041 & 7.333 & 77.47 & 90.06 & 82.91 \\
\hline $\operatorname{str} 7$ & -118.557 & 1.272 & $\mathrm{P} 21 / \mathrm{n}$ & 10.409 & 7.399 & 11.568 & 90.00 & 104.52 & 90.00 \\
\hline str 8 & -118.285 & 1.256 & $\mathrm{P} 2_{1}$ & 9.120 & 6.783 & 15.188 & 90.00 & 111.58 & 90.00 \\
\hline str 9 & -117.972 & 1.247 & P-1 & 6.845 & 9.134 & 7.430 & 107.54 & 96.03 & 85.36 \\
\hline str 10 & -117.547 & 1.242 & $\mathrm{P} 2_{1}$ & 9.096 & 14.398 & 6.762 & 90.00 & 94.07 & 90.00 \\
\hline str 11 & -117.545 & 1.261 & $\mathrm{P} 2{ }_{1} 2_{1} 2_{1}$ & 14.213 & 6.733 & 9.094 & 90.00 & 90.00 & 90.00 \\
\hline str 12 & -117.475 & 1.259 & P2111 & 14.232 & 6.730 & 9.097 & 89.46 & 90.00 & 90.00 \\
\hline str 13 & -117.389 & 1.245 & P-1 & 10.837 & 6.889 & 10.264 & 132.40 & 98.10 & 56.86 \\
\hline str 14 & -117.134 & 1.282 & $\mathrm{P} 22_{1} 2_{1}$ & 11.716 & 8.562 & 8.531 & 90.00 & 90.00 & 90.00 \\
\hline $\operatorname{str} 15$ & -116.953 & 1.221 & $\mathrm{P} 22_{1}$ & 9.061 & 6.695 & 8.007 & 90.00 & 112.29 & 90.00 \\
\hline str 16 & -116.941 & 1.252 & $\mathrm{P} 2_{1}$ & 7.660 & 6.824 & 18.108 & 90.00 & 67.82 & 90.00 \\
\hline str 17 & -116.739 & 1.196 & $\mathrm{P} 21 / \mathrm{n}$ & 9.940 & 8.650 & 10.674 & 90.00 & 88.19 & 90.00 \\
\hline str 18 & -116.480 & 1.247 & $\mathrm{Pc}$ & 6.851 & 18.144 & 14.157 & 90.00 & 88.40 & 90.00 \\
\hline str 19 & -116.426 & 1.251 & $\mathrm{Cc}$ & 12.138 & 11.325 & 9.373 & 90.00 & 137.09 & 90.00 \\
\hline $\operatorname{str} 20$ & -116.260 & 1.256 & $\mathrm{Pc}$ & 9.105 & 7.391 & 13.055 & 90.00 & 96.26 & 90.00 \\
\hline str 158 & -111.055 & 1.201 & $\mathrm{P} 2{ }_{1} 2_{1} 2_{1}$ & 24.080 & 4.541 & 8.353 & 90.00 & 90.00 & 90.00 \\
\hline str 210 & -109.865 & 1.213 & $\mathrm{P} 22_{1} 2_{1}$ & 5.010 & 21.792 & 8.282 & 90.00 & 90.00 & 90.00 \\
\hline str 302 & -108.555 & 1.215 & $\mathrm{P} 2_{1} / \mathrm{c}$ & 8.320 & 5.117 & 21.235 & 90.00 & 92.33 & 90.00 \\
\hline str 362 & -107.766 & 1.185 & $\mathrm{P} 2{ }_{1} / \mathrm{c}$ & 8.399 & 4.521 & 24.384 & 90.00 & 90.34 & 90.00 \\
\hline
\end{tabular}

Table 1. List of Lowest energy conformers of benzocaine with the reproduced experimentally observed polymorphs of Benzocaine. 


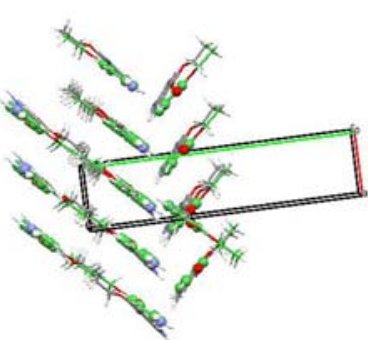

a)

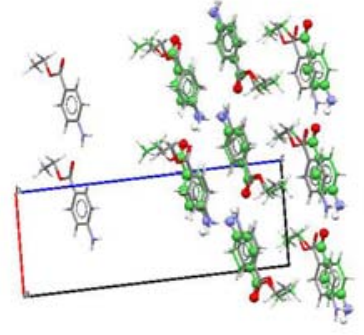

b)

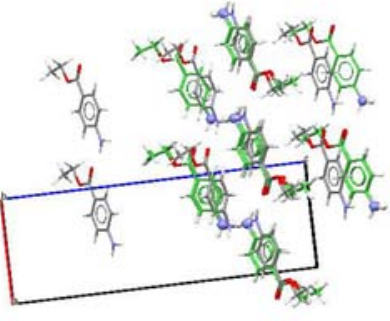

c)

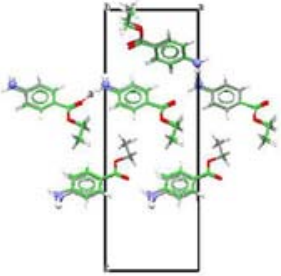

d)

Fig. 3. Crystal packing similarity between a) Str210(blue) and Form II (green) b) Str 302 (blue) and Form I (green) c) Str 362 (blue) and Form I (green) d) Str 158(blue) and Form II (green) with 20 molecules in common in a coordination sphere. [Str 210, Str 302, Str 362 and Str 158 are theoretically predicted conformers, Form I and II are experimental known polymorphs.]

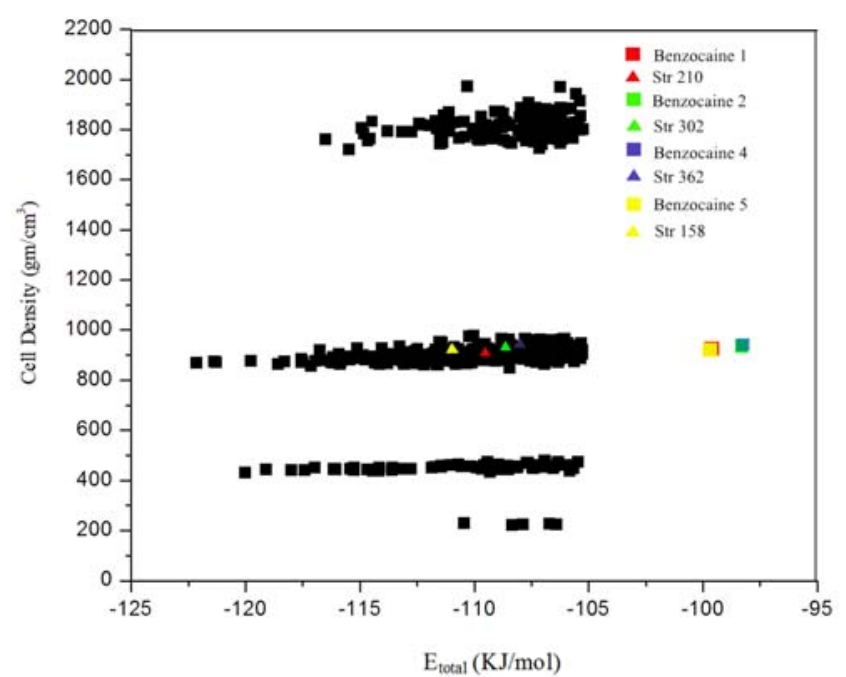

Fig. 4. Energy landscape consisting the possible conformers of benzocaine associating the $\mathrm{E}_{\text {total }}$ rated landscape. The COMPACK comparison of the unique structures with experimental forms of benzocaine employing the criterion of 20 molecules in common for the coordination sphere with least RMSD in crystal packing similarity revealed that the str 158 , str 210 , str 302 and str 362 (optimized conformers generated at the $158,210,302$ and 362 position in the energy rank with $\mathrm{E}_{\text {total }}-111.055 \mathrm{KJ} / \mathrm{mol},-109.865 \mathrm{KJ} / \mathrm{mol},-108.555$ $\mathrm{KJ} / \mathrm{mol}$ and $-107.766 \mathrm{KJ} / \mathrm{mol}$ respectively) resembles to the experimental benzocaine Form $\mathrm{I}\left(\mathrm{E}_{\text {total }}-99.710\right.$ $\mathrm{KJ} / \mathrm{mol}$ and $\left.\mathrm{E}_{\text {total }}-99.676 \mathrm{KJ} / \mathrm{mol}\right)$ and II $\left(\mathrm{E}_{\text {total }}-98.293\right.$ $\mathrm{KJ} / \mathrm{mol}$ and $\mathrm{E}_{\text {total }}-98.278 \mathrm{KJ} / \mathrm{mol}$ ) [Str 158 and $\mathrm{Str} 210$ resembled FORM II and Str 302 and Str 362 resembled Form I] Fig 3.

The equivalent nature of the optimized conformers with the experimental forms were analyzed from the comparative analysis of the lattice parameters (Table 2), intermolecular short contacts and the mechanical stability of the structures at $0 \mathrm{~K}$.

Table 2. Regeneration of the crystal structures of Benzocaine molecule using the experimental data, minimized experimental conformation (Expminexp) and the matching structures (20 molecules in common) found during the search of conformers.

\begin{tabular}{|c|c|c|c|c|c|c|c|c|c|c|}
\hline Structures & $a(\AA)$ & $b(\AA)$ & $c(\AA)$ & $\alpha\left(^{\circ}\right)$ & $\beta\left(^{\circ}\right)$ & $g\left({ }^{\circ}\right)$ & Volume & Density & $\begin{array}{c}\mathbf{E}_{\text {total }} \\
(\mathbf{K J} / \mathbf{m o l})\end{array}$ & rmsd \\
\hline \multicolumn{11}{|l|}{ Benz1 (Form II) } \\
\hline Observed & 5.302 & 8.217 & 20.87 & 90 & 90 & 90 & 909.234 & & & \\
\hline Expminexp & 4.713 & 8.363 & 23.373 & 90.00 & 90.00 & 90.00 & 921.118 & 1.191 & -99.676 & \\
\hline Expminopt (Str 210) & 5.010 & 21.792 & 8.282 & 90.00 & 90.00 & 90.00 & 904.230 & 1.213 & -109.865 & 0.46 \\
\hline \multicolumn{11}{|l|}{ Benz2(Form I) } \\
\hline Observed & 8.198 & 5.43 & 19.592 & 90 & 91.35 & 90 & 871.899 & & & \\
\hline Expminexp & 8.235 & 6.069 & 18.746 & 90.00 & 92.45 & 90.00 & 935.981 & 1.172 & -98.293 & \\
\hline Expminopt(Str 302) & 8.320 & 5.117 & 21.235 & 90.00 & 92.33 & 90.00 & 903.256 & 1.215 & -108.555 & 0.9 \\
\hline \multicolumn{11}{|l|}{ Benz4(Form I) } \\
\hline Observed & 8.257 & 5.5009 & 19.956 & 90 & 91.699 & 90 & 906.022 & & & \\
\hline Expminexp & 8.235 & 6.069 & 18.747 & 90.00 & 92.52 & 90.00 & 936.081 & 1.172 & -98.278 & \\
\hline Expminopt (Str 362) & 8.399 & 4.521 & 24.384 & 90.00 & 90.34 & 90.00 & 925.940 & 1.185 & -107.766 & 1.97 \\
\hline \multicolumn{11}{|l|}{ Benz5(Form II) } \\
\hline Observed & 8.2424 & 5.3111 & 20.9044 & 90 & 90 & 90 & 915.115 & & & \\
\hline Expminexp & 8.364 & 4.706 & 23.397 & 90.00 & 90.00 & 90.00 & 920.981 & 1.191 & -99.710 & \\
\hline Expminopt (Str 158) & 24.080 & 4.541 & 8.353 & 90.00 & 90.00 & 90.00 & 913.272 & 1.201 & -111.055 & 0.29 \\
\hline
\end{tabular}


The table exposed the equivalent nature of the optimized conformers with the known experimental forms with similar lattice parameters. The deviation of the energy associated with the structures might be due to the temperature dependence of the molecule as it were regenerated at $0 \mathrm{~K}$. The equivalence of crystal phase between experimentally determined and predicted structures were authenticated from the peaks generated at the simulated XRD patterns of the structures (Fig. 5-Fig. 8).

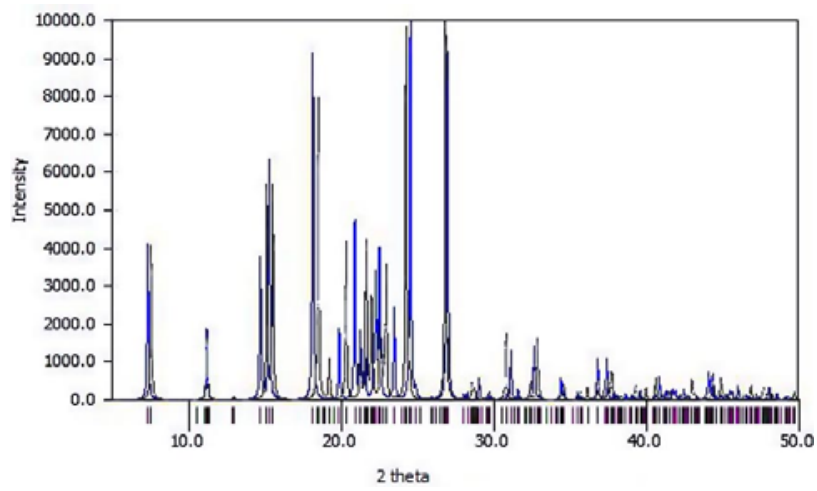

Fig. 5. Comparison of the XRD spectrum of Str 158 (black) and Form II (benz5) (blue)

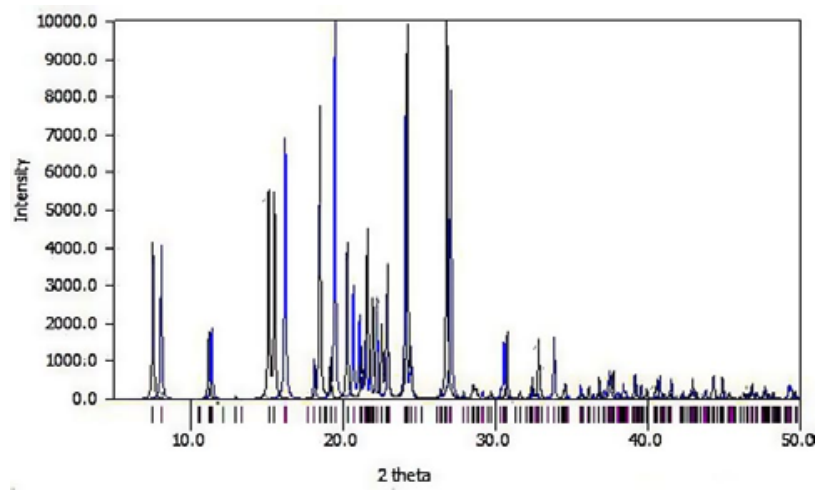

Fig. 6. Comparison of the XRD spectrum of Str 210 (black) and Form II (benz1)(blue)

The studies indicated that the predicted structures were stable from the presence of the highest peaks. The shift in the XRD pattern were due to the shear factor associated with the molecules at $0 \mathrm{~K}$. The analysis have also exposed the str 158 and str 302 were exhibiting more perfect match in the XRD. The hydrogen bonds prevails in the predicted and experimental polymorphs of benzocaine were studied in detail and tabulated. The hydrogen bond analysis revealed the experimental polymorphs and predicted equivalent were stabilized from the $\mathrm{N}-\mathrm{H}-\mathrm{O}$ interactions between the carbonyl oxygen attached to the terminal with the amide group attached to the aromatic ring of the molecule contributing to the chain type graph set of $\mathrm{C}_{1}{ }^{1} 8$ and. In addition to the carbonyl -amide interaction, the predicted structures (str 210, str 302 and str 362) and their corresponding equivalent experimental form of II and I were found to be stabilized by the $\mathrm{C}-\mathrm{H}-\mathrm{O}$ interaction through the aromatic carbon atoms beside to the aromatic nitrogen and the carbonyl oxygen atom along with the interaction of Carbon atom at the terminal ethyl group with the carbonyl oxygen. The notable result were observed for the str158 in which the carbon atom of the terminal methyl group interacts with the oxygen atom of the carbonyl functional group. The common hydrogen

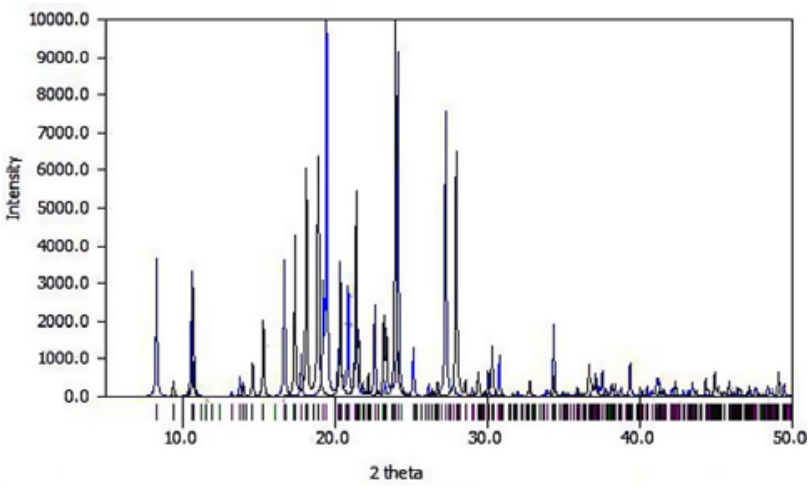

Fig. 7. Comparison of the XRD spectrum of Str 302 (black) and Form I (benz2) (blue)

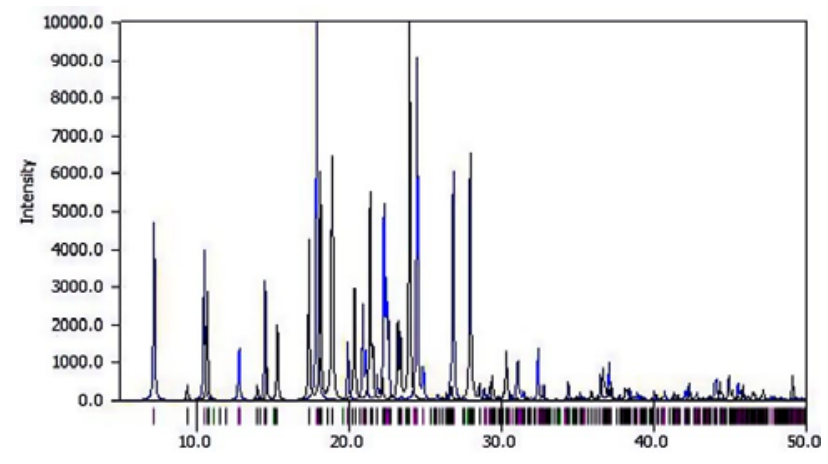

Fig. 8. Comparison of XRD spectrum of Str 362 (black) and Form I (benz4)(blue)

bond interactions that are likely to crystallize the conformers were listed in Table 3.

Table 3. Common intermolecular H-Bonds between the experimental and Predicted conformers.

\begin{tabular}{llccc}
\hline $\begin{array}{l}\text { Predicted } \\
\text { conformers }\end{array}$ & $\begin{array}{l}\text { Common } \\
\text { H-bonds }\end{array}$ & $\begin{array}{l}\text { Experimental } \\
\text { forms }\end{array}$ \\
\hline str 158 & $\mathrm{N}-\mathrm{H}-\mathrm{O}$ & $\mathrm{C}-\mathrm{H}-\mathrm{O}$ & $\mathrm{N}-\mathrm{H}-\mathrm{N}$ & Form II benz5 \\
str 210 & $\mathrm{~N}-\mathrm{H}-\mathrm{O}$ & $\mathrm{C}-\mathrm{H}-\mathrm{O}$ & - & Form II benz1 \\
str 302 & $\mathrm{N}-\mathrm{H}-\mathrm{O}$ & $\mathrm{C}-\mathrm{H}-\mathrm{O}$ & - & Form I benz2 \\
str 362 & $\mathrm{N}-\mathrm{H}-\mathrm{O}$ & $\mathrm{C}-\mathrm{H}-\mathrm{O}$ & - & Form I benz4 \\
\hline
\end{tabular}

The in match nature of the hydrogen bonds for the predicted structures and the experimental equivalent justi- 

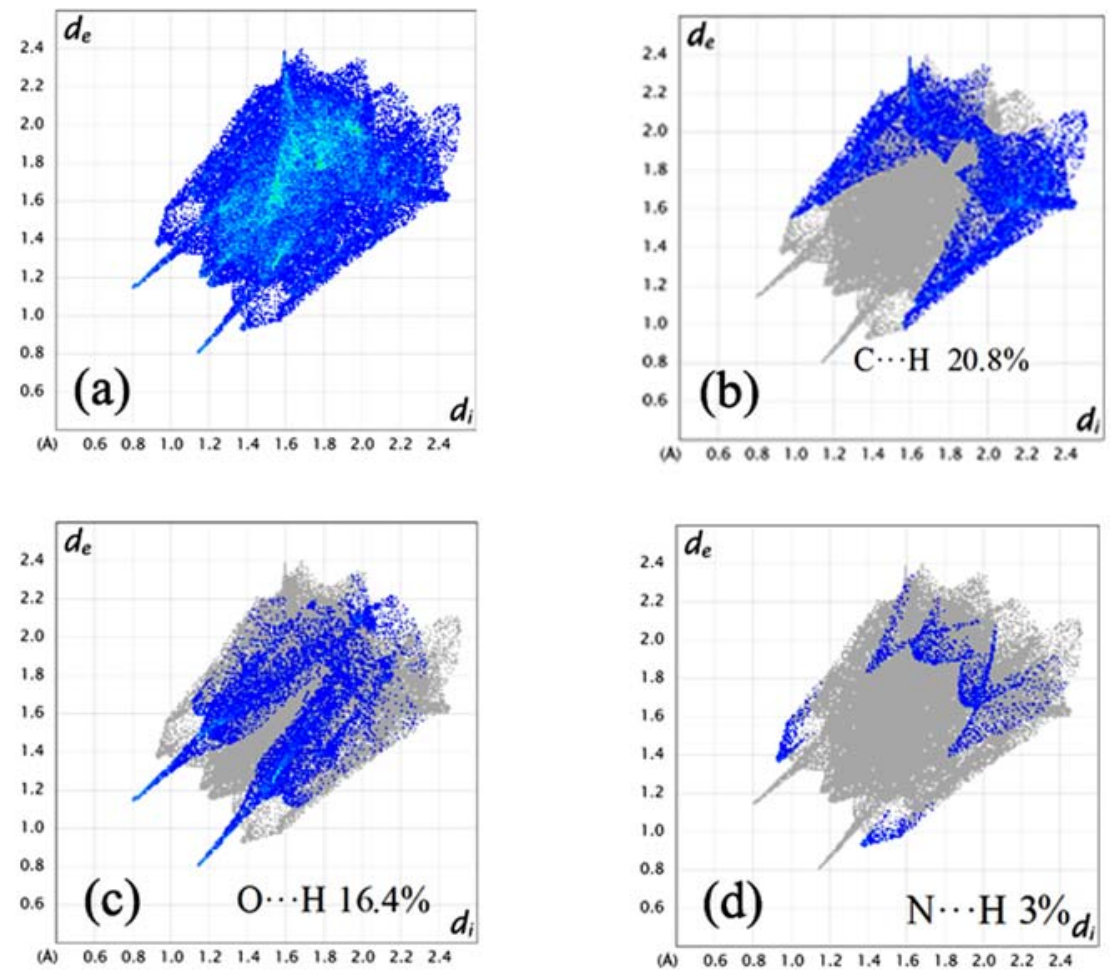

Fig. 9. 2D Finger print plot of experimental Form II with a) $100 \%$ contribution of all elements b) $20.8 \%$ of $\mathrm{C} \cdots \mathrm{H} / \mathrm{H} \cdots \mathrm{C}$ interaction c) $16.4 \%$ $\mathrm{O} \cdots \mathrm{H} / \mathrm{H} \cdots \mathrm{O}$ interaction d) $3 \%$ of $\mathrm{N} \cdots \mathrm{H} / \mathrm{H} \cdots \mathrm{N}$ interaction.
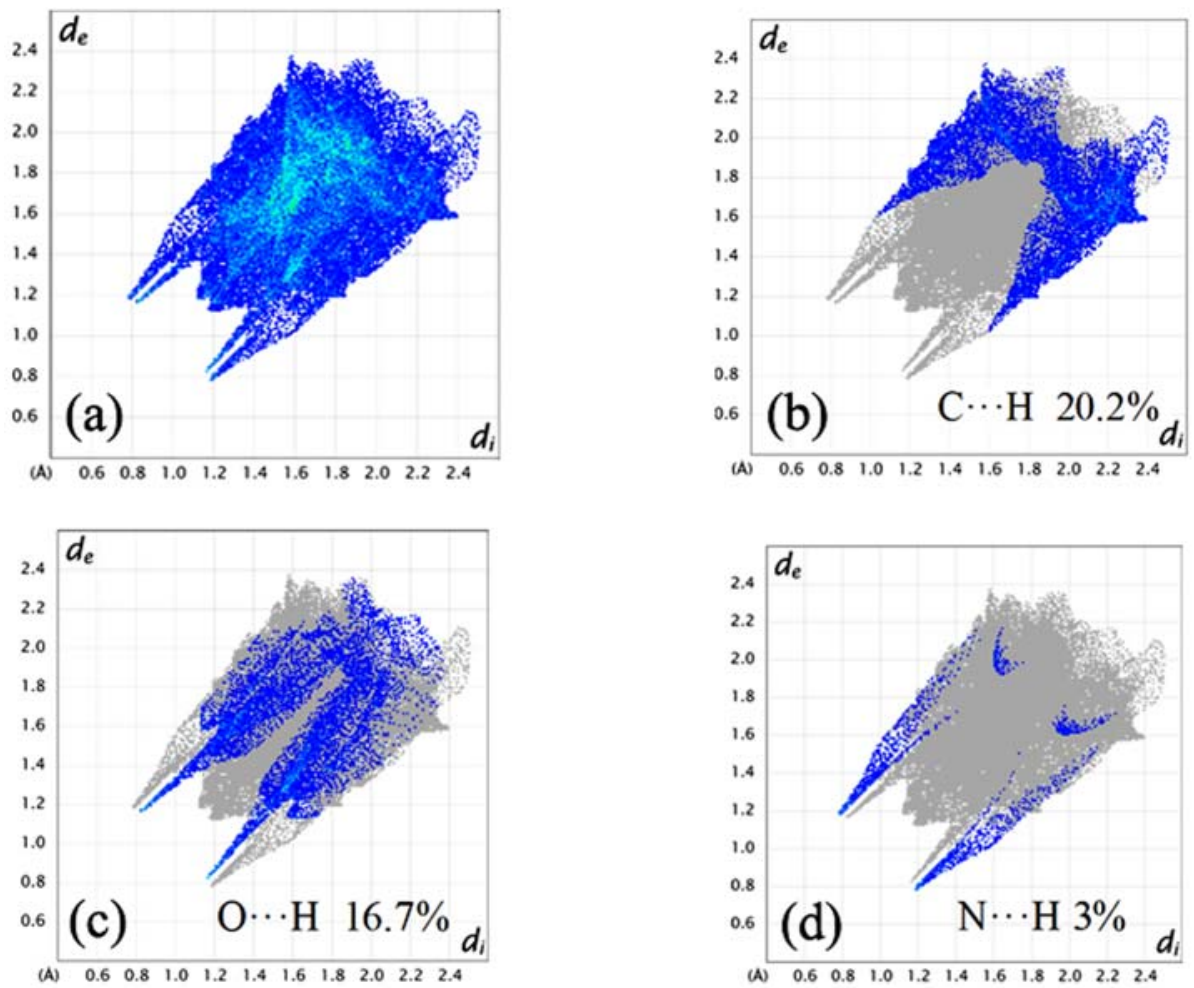

Fig. 10. 2D Finger print plot of Str 158 with a) $100 \%$ contribution of all elements b) $20.2 \%$ of $\mathrm{C} \cdots \mathrm{H} / \mathrm{H} \cdots \mathrm{C}$ interaction c) $16.7 \% \mathrm{O} \cdots \mathrm{H} / \mathrm{H} \cdots \mathrm{O}$ interaction d) $3 \%$ of $\mathrm{N} \cdots \mathrm{H} / \mathrm{H} \cdots \mathrm{N}$ interaction. 

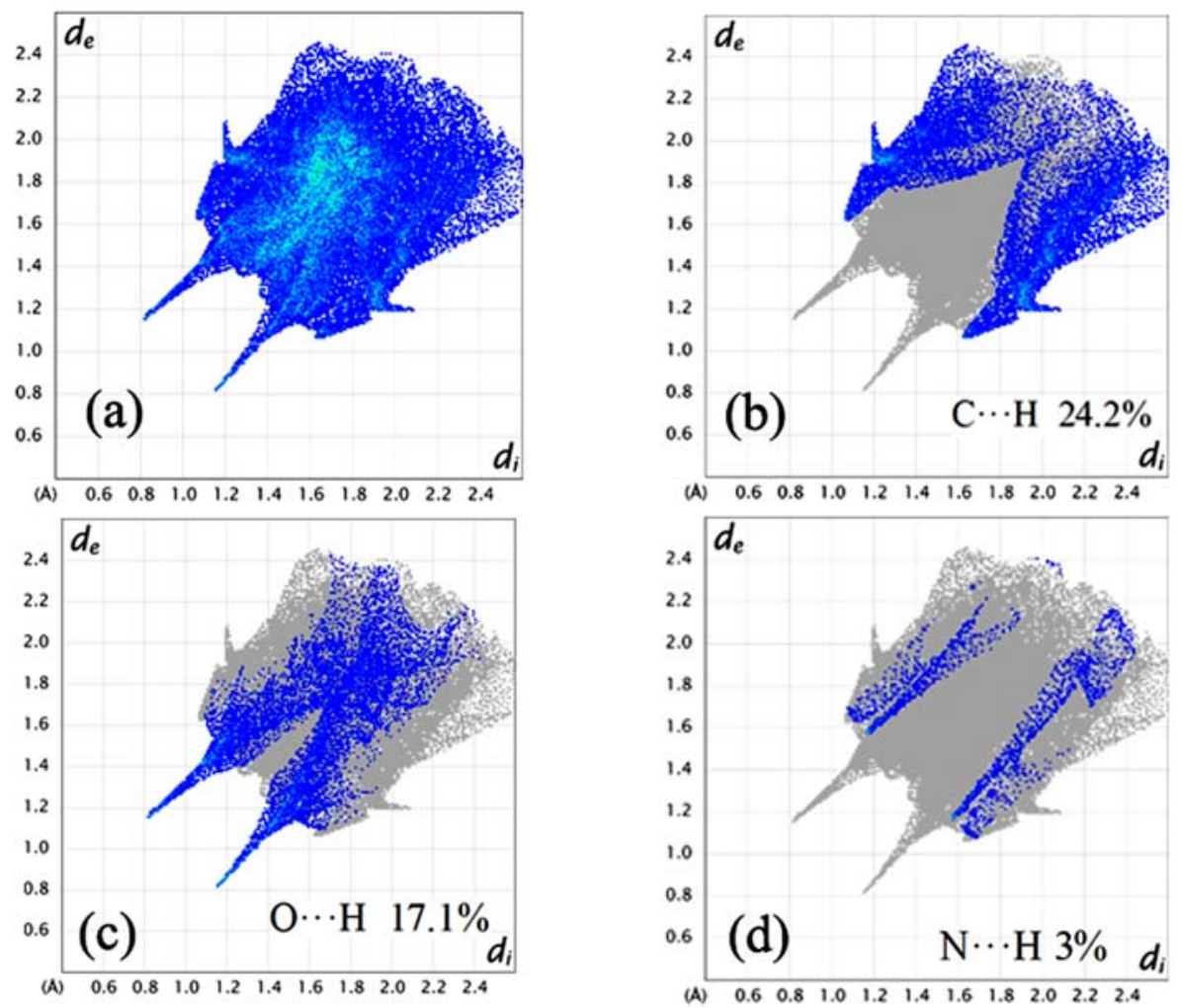

Fig. 11. 2D Finger print plot of experimental Form II with a) $100 \%$ contribution of all elements b) $24.2 \%$ of $\mathrm{C} \cdots \mathrm{H} / \mathrm{H} \cdots \mathrm{C}$ interaction c) $17.1 \%$ $\mathrm{O} \cdots \mathrm{H} / \mathrm{H} \cdots \mathrm{O}$ interaction d) $3 \%$ of $\mathrm{N} \cdots \mathrm{H} / \mathrm{H} \cdots \mathrm{N}$ interaction.
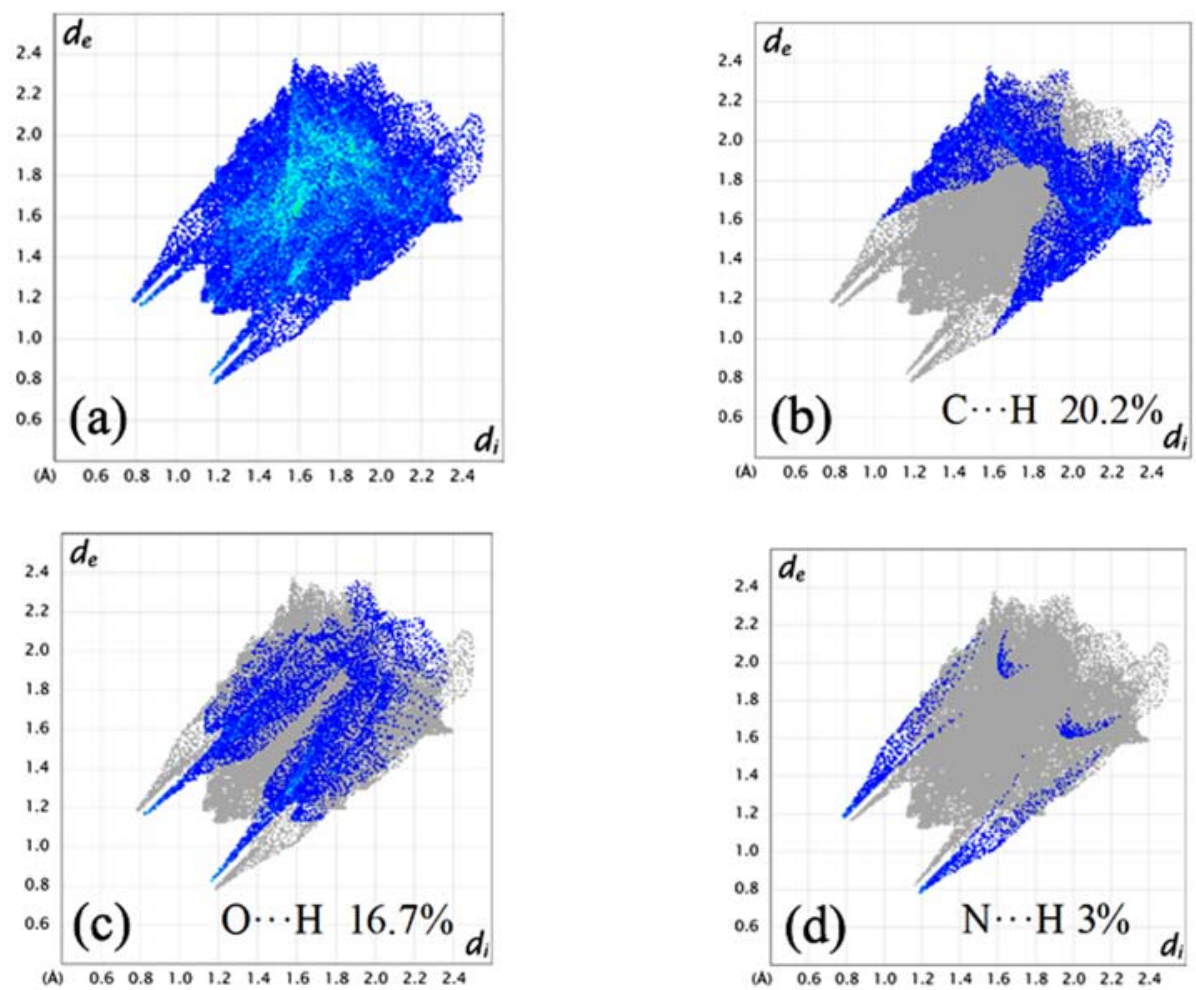

Fig. 12. 2D Finger print plot of Str 302 with a) $100 \%$ contribution of all elements b) $25.7 \%$ of $\mathrm{C} \cdots \mathrm{H} / \mathrm{H} \cdots \mathrm{C}$ interaction c) $17.5 \% \mathrm{O} \cdots \mathrm{H} / \mathrm{H} \cdots \mathrm{O}$ interaction d) $3 \%$ of $\mathrm{N} \cdots \mathrm{H} / \mathrm{H} \cdots \mathrm{N}$ interaction. 
fies the accuracy of the prediction methodology and energy landscape. The detailed analysis and comparative studies of the hydrogen bonds and the peaks of the simulated XRD exhibited the perfect match of str 158 and str 302 with the polymorphic form of benzocaine II and I with least RMSD of 0.294 and 0.9 in crystal packing similarity; were selected for further studies. The percentage of contribution of the key intermolecular interactions to the crystal stability were studied from the Hirshfeld surface.

\section{2. Hirshfeld Finger Print Plot Analysis}

The contribution of the vital interatomic interaction in the crystal stability and crystallization of the benzocaine molecule have been studied thoroughly from the Hirshfeld surface and $2 \mathrm{D}$ contour plots generated using the Crystal Explorer software package. ${ }^{20}$

The Hirshfeld analysis of the experimental benzocaine molecule of form I and Form II with the predicted equivalent structures, str 302 and str 158 emphasized the perfect match. The crystal were found to be stabilized $\mathrm{N}-\mathrm{H}-\mathrm{O}$ and $\mathrm{C}-\mathrm{H}-\mathrm{O}$ interactions, were the latter interaction providing average of $22.5 \%$ percentage of the overall contribution to the stability of the conformers. The pointed nature of the $\mathrm{O}-\mathrm{H} / \mathrm{H}-\mathrm{O}$ interactions towards the lower points of the di/de region indicates the vital importance of the interaction in the stability. The 2D contour plot of the $\mathrm{N}-\mathrm{H} / \mathrm{H}-\mathrm{N}$ interaction also shows it importance from the pointed nature with a percentage of contribution of $3 \%$. The in match and perfect similarity of the predicted conformers and the experimental equivalents authenticates str 158 and str 302 as known experimental forms of Form II and Form I of benzocaine, thereby validating the energy landscape. As the mechanical properties are closely related to several material parameters which are within reach of theoretical calculations. ${ }^{21}$ Studies have been made to analyze the mechanical strength of the experimental polymorphs and the equipotential predicted structure from the elastic components of the Cij matrix. ${ }^{22}$ henticated the energy landscape. The structures generated at the lowest energy region of the energy landscape are the possible polymorphs of the benzocaine.

\section{3. Analysis of the Predicted Lowest Energy Polymorph of Benzocaine (Str 1)}

The authenticity of the lattice minimized energy landscape generated from the hypothetical unique structures of benzocaine conformers justified the existence of possible stable polymorphs at the lowest energy region. The optimized monoclinic crystal structure of the benzocaine polymorph ( Fig. 13) generated with $\mathrm{E}_{\text {total }}$ $-122.126 \mathrm{KJ} / \mathrm{mol}$ and space group $\mathrm{P} 2_{1} / \mathrm{c}$ was analyzed in detail to expose the mechanical stability and the morphological importance.

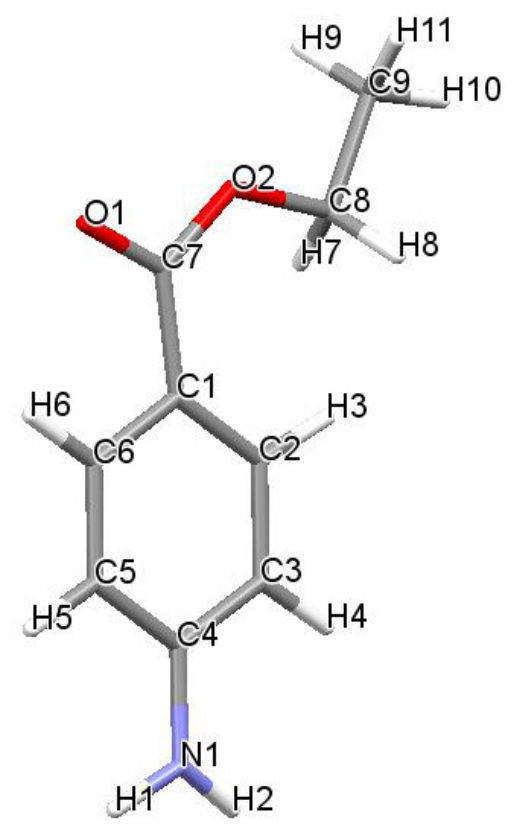

Fig. 13. The optimized crystal structure of benzocaine polymorph generated as Str 1.

Table 4: Comparison of the mechanical properties of the ab initio predicted benzocaine crystal structure and experimental polymorphs of Benzocaine at $0 \mathrm{~K}$.

\begin{tabular}{lcccrrrr}
\hline Structures & $\boldsymbol{C}_{\boldsymbol{1 1}}$ & $\boldsymbol{C}_{\mathbf{2 2}}$ & $\boldsymbol{C}_{\mathbf{3 3}}$ & $\boldsymbol{C}_{\mathbf{4 4}}$ & $\boldsymbol{C}_{55}$ & $\boldsymbol{C}_{\mathbf{6 6}}$ & $\begin{array}{c}\text { Young's } \\
\text { modulus } \\
\text { (GPa) }\end{array}$ \\
\hline Form II & 44.633 & 14.617 & 26.010 & 9.705 & 13.306 & 8.962 & 24.038 \\
Str158 & 34.230 & 18.098 & 50.619 & 11.086 & 21.688 & 13.444 & 31.231 \\
Form I & 47.385 & 17.706 & 19.711 & 9.459 & 6.316 & 10.053 & 21.440 \\
Str302 & 51.709 & 20.661 & 26.242 & 10.797 & 15.312 & 8.607 & 26.883 \\
\hline
\end{tabular}

The diagonal elements of the Hessian matrix are found to be positive and definite; revealed that the structures have met born criteria and are mechanically stable at $0 \mathrm{~K} .{ }^{23}$ The perfect match of the parameters between the experimental and predicted polymorphs of benzocaine aut-
The benzocaine conformer generated at the global minima was found to be mechanically stable at $0 \mathrm{~K}$ by achieving born criteria of stability with elastic sensitivity of 29.89GPa. The thermodynamic stability of the global minimum (explained as Str 1 henceforward) were justified 

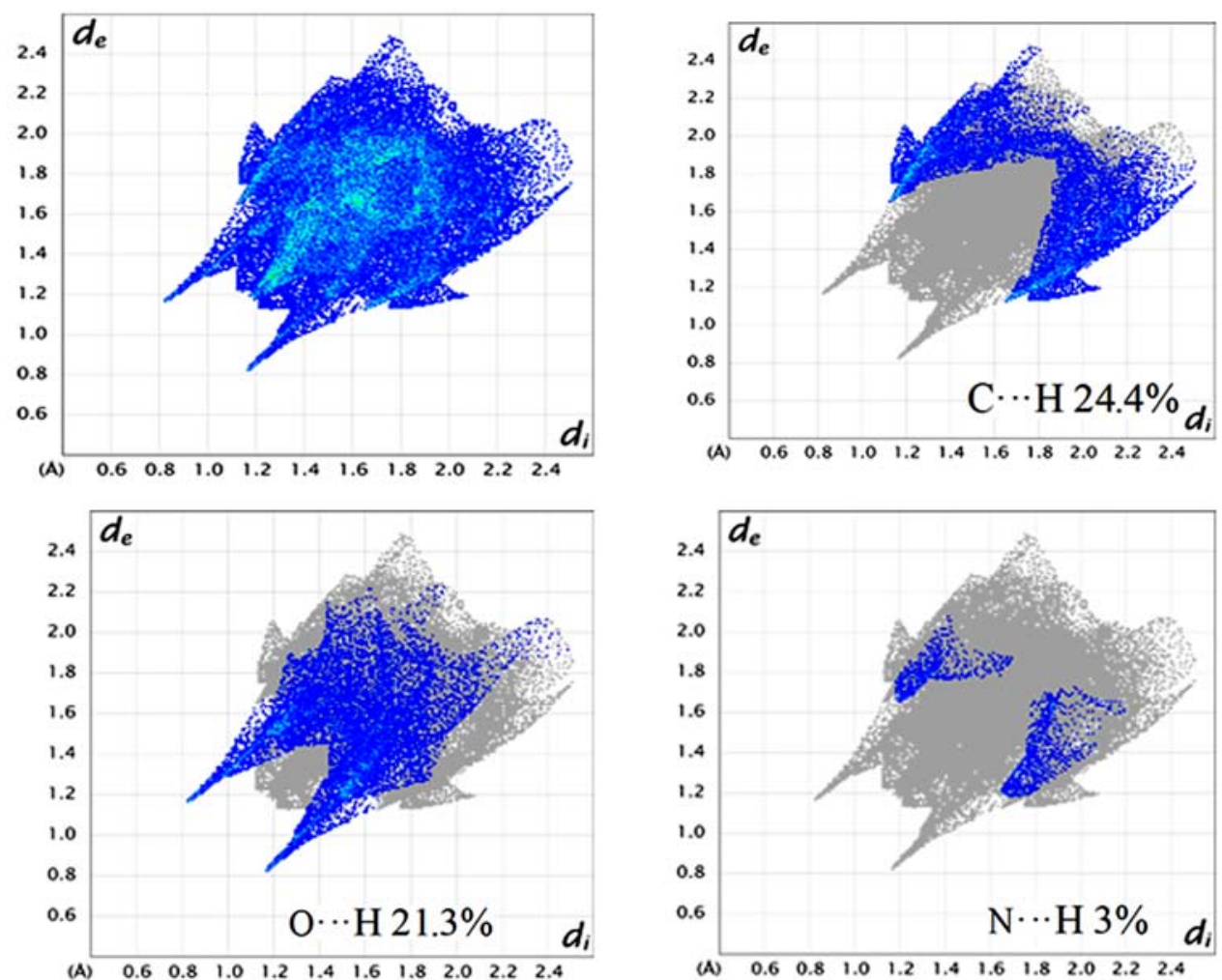

Fig. 14: 2D Finger print plot of predicted Str 1 with a) $100 \%$ contribution of all elements b) $24.4 \%$ of $\mathrm{C} \cdots \mathrm{H} / \mathrm{H} \cdots \mathrm{C}$ interaction c) $21.3 \% \mathrm{O} \cdots \mathrm{H} / \mathrm{H} \cdots \mathrm{O}$ interaction d) $3 \%$ of $\mathrm{N} \cdots \mathrm{H} / \mathrm{H} \cdots \mathrm{N}$ interaction.

from the Intermolecular attraction prevailed on the system. The H-bond analysis of Str 1 reveals that the structure were found to be stable by establishing the intermolecular interaction among the Nitrogen atom of the amide group $\mathrm{N}(1)$ attached to the ring and $\mathrm{O}(2)$, generating $\mathrm{C} 11$ (8) graph set through $\mathrm{N}(1)-\mathrm{H}(2)-\mathrm{O}(2)$ linkage. The detailed analysis have also revealed the Carbon atoms of the terminal ethyl group interacts with the carbonyl oxygen making a bond length of $3.401 \AA$ with an angle of $122^{\circ}$ through $\mathrm{C}(8)-\mathrm{H}(7)-\mathrm{O}(1)$. The identification studies of the possible hydrogen bonds prevailed in the Str 1 also exposed a key interaction via $\mathrm{H}(7)$ between $\mathrm{C}(8)$ and $\mathrm{O}(1)[\mathrm{C}(8)-\mathrm{H}(7)-\mathrm{O}(1)]$ making an angle of $122.5^{\circ}$ with bond length $3.401 \AA$, in addition the methyl carbon atom $\mathrm{C}(9)$ also found to be bonded with the amide nitrogen (N(1)) with bond angle $155.5^{\circ}$ and bond length $3.865 \AA$.

The Hirshfeld analysis and the 2D contour plots of str1 detailed the percentage of contribution of each interaction towards the crystal stability.

The percentage of contribution of the key interactions exhibit the dominant nature of the $\mathrm{O}-\mathrm{H}$ interaction Oxygen being the acceptor, from the pointed nature of the $2 \mathrm{D}$ contour plot towards the lower region of $d i / d e$. The interaction contributes to the $21.3 \%$ of the hirshfeld surface, where as the $\mathrm{C}-\mathrm{H}$ interaction contributes $24.4 \%$ of the surface. The hirshfeld surface reflected the stability of the crystal structure from the $\mathrm{N}-\mathrm{H}-\mathrm{O}$ bonding, justifying the thermodynamical satbility of Str 1 from the pointed nature of the fingerprint plot .

The simulated XRD patterns were generated for the global minimum structure of benzocaine at $0 \mathrm{~K}$. The XRD graphs was found to be exhibiting high peaks at different 2 values. The diffraction patterns are represented in fig. 15

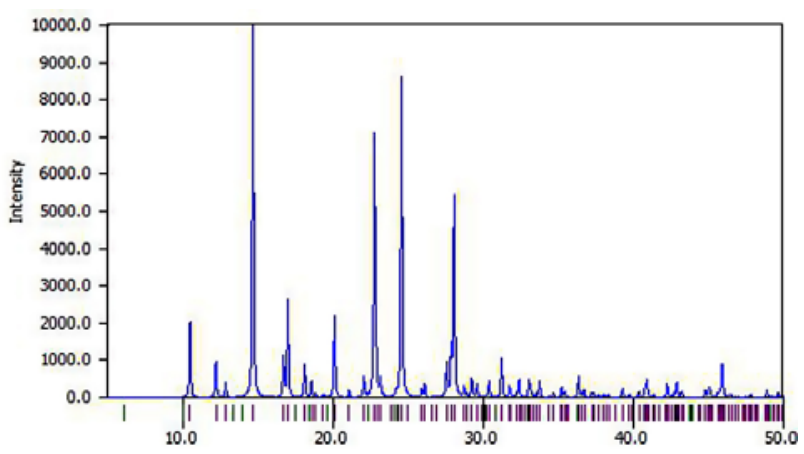

Fig. 15: Simulated XRD pattern of the Predicted polymorph (Str 1)

As the morphological importance of crystal structure depends on the growth rate and surface area of the crystal phases, studies have been carried out to interpret the morphology and the growth rate of str1by calculating the interplanar d spacing through the formula (3) 


$$
\begin{aligned}
1 / \mathrm{d}^{2}{ }_{\mathrm{hkl}}= & (1 / \sin \beta)\left(h^{2} / a^{2}+k^{2} \sin ^{2} \beta / b^{2}+l^{2} /\right. \\
& \left.c^{2}-2 l h \cos \beta / \mathrm{ac}\right)
\end{aligned}
$$

The morphological analysis of the structure have been carries out by using the BFDH theory ${ }^{24,25,26}$ incorporating the interplanar spacing $\left(\boldsymbol{d}_{\mathrm{hkl}}\right)$ and the crystal symmetry which provide a good insight to the morphology of the polymorphs (fig. 16).

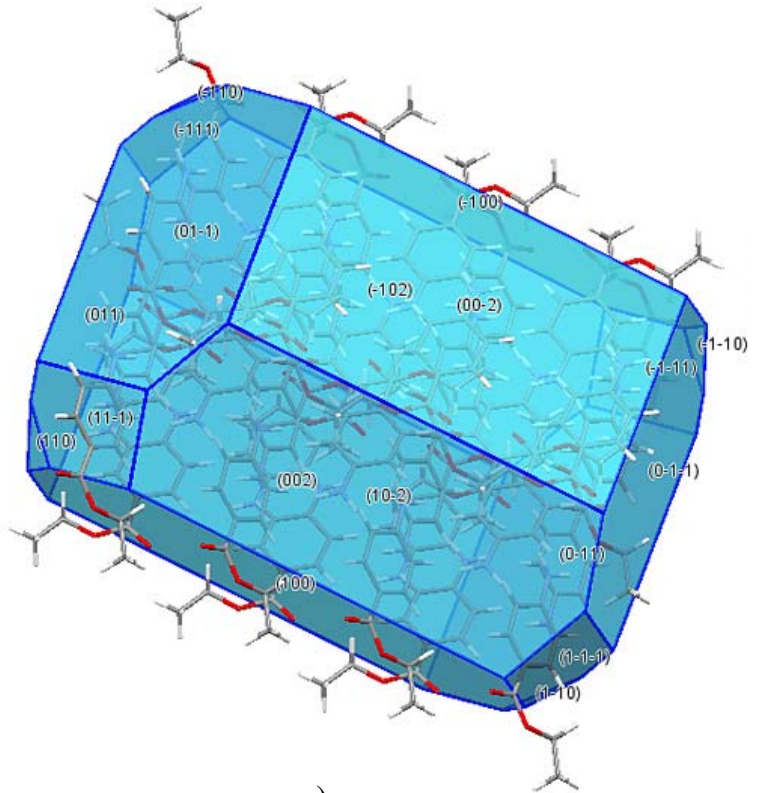

a) miller indices of $\left(\begin{array}{lll}-1 & 0 & 0\end{array}\right)$ and $\left(\begin{array}{lll}1 & 0 & 0\end{array}\right)$ are morphologically important due to their comparatively less growth rate by exhibiting the higher $d_{\text {spacing. }}^{27}$

The theoretical analysis of the Str 1 revealed that the structure is a thermodynamically possible stable monoclinic polymorph of Benzocaine, which have the ability to crystallize by attaining intermolecular short contacts with stabilized dense packing.

Fig. 16: Predicted morphology of Str 1 with a) longitudinal view b) Transverse view.

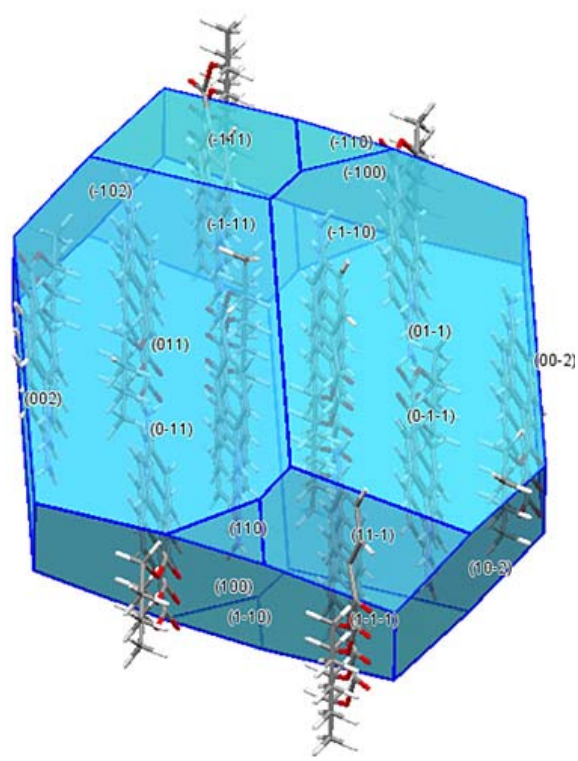

b)
The growth rate of the each miller indices have been noted and tabulated to expose the morphologically important of the structure (Table 5) . The studies have revealed

\section{Conclusion}

$\mathrm{Ab}$ initio prediction of the possible stable polymorph of benzocaine molecule, a flexible local anesthetic

Table 5: List of the predicted miller indices of Str 1 with interplanar d spacing.

\begin{tabular}{rrrccccccc}
\hline $\boldsymbol{h}$ & $\boldsymbol{k}$ & $\boldsymbol{L}$ & $\mathbf{a}$ & $\mathbf{B}$ & $\mathbf{C}$ & $\boldsymbol{a}$ & $\boldsymbol{B}$ & $\boldsymbol{\gamma}$ & $\boldsymbol{D}$ \\
\hline-1 & 1 & 1 & 9.056 & 6.6302 & 15.5501 & 90 & 111.4606 & 90 & 5.12 \\
-1 & 1 & 0 & 9.056 & 6.6302 & 15.5501 & 90 & 111.4606 & 90 & 5.35 \\
0 & 1 & -1 & 9.056 & 6.6302 & 15.5501 & 90 & 111.4606 & 90 & 6.10 \\
0 & 1 & 1 & 9.056 & 6.6302 & 15.5501 & 90 & 111.4606 & 90 & 6.10 \\
1 & 1 & 0 & 9.056 & 6.6302 & 15.5501 & 90 & 111.4606 & 90 & 5.35 \\
1 & 1 & -1 & 9.056 & 6.6302 & 15.5501 & 90 & 111.4606 & 90 & 5.12 \\
0 & 0 & 2 & 9.056 & 6.6302 & 15.5501 & 90 & 111.4606 & 90 & 7.76 \\
1 & 0 & 0 & 9.056 & 6.6302 & 15.5501 & 90 & 111.4606 & 90 & 9.04 \\
-1 & 0 & 2 & 9.056 & 6.6302 & 15.5501 & 90 & 111.4606 & 90 & 6.09 \\
1 & 0 & -2 & 9.056 & 6.6302 & 15.5501 & 90 & 111.4606 & 90 & 6.09 \\
-1 & 0 & 0 & 9.056 & 6.6302 & 15.5501 & 90 & 111.4606 & 90 & 9.04 \\
0 & 0 & -2 & 9.056 & 6.6302 & 15.5501 & 90 & 111.4606 & 90 & 7.76 \\
0 & -1 & 1 & 9.056 & 6.6302 & 15.5501 & 90 & 111.4606 & 90 & 6.10 \\
0 & -1 & 1 & 9.056 & 6.6302 & 15.5501 & 90 & 111.4606 & 90 & 6.10 \\
-1 & -1 & 1 & 9.056 & 6.6302 & 15.5501 & 90 & 111.4606 & 90 & 5.12 \\
-1 & -1 & 0 & 9.056 & 6.6302 & 15.5501 & 90 & 111.4606 & 90 & 5.35 \\
1 & -1 & 0 & 9.056 & 6.6302 & 15.5501 & 90 & 111.4606 & 90 & 5.35 \\
-1 & -1 & -1 & 9.056 & 6.6302 & 15.5501 & 90 & 111.4606 & 90 & 4.99 \\
\hline
\end{tabular}


molecule via generating the energy landscape; by analyzing the energy associated for each different conformers showed good accuracy in generating the possible crystal structures of benzocaine. The conformers with compromising energy penalty of torsional distortions were successfully generated the hypothetical structures, owing to the global search through the repulsion alone potential field. The lattice minimization using the distributed multipole analysis associated with the hypothetical structures authenticated the methodology from the generation of experimental equivalent polymorph of benzocaine. The comparison analysis of the experimental known polymorph of benzocaine with predicted hypothetical conformers revealed that Str 158 and Str 302 were equivalent to the experimental known polymorphs of Form II and Form I, with packing rmsd of 0.294 and 0.9 respectively. The thermodynamic stability crystal nature of the predicted conformers was proved from the simulated XRD patterns, with perfect match of Str 158 and Str 302 with Form II and Form I respectively. The Hirshfeld analysis indicated that the predicted and experimental polymorphs of benzocaine were stabilized through $\mathrm{N}-\mathrm{H}-\mathrm{O}$ and $\mathrm{C}-\mathrm{H}-\mathrm{O}$ interactions with dominant interaction through the carbonyl Oxygen atom. As the landscape was authenticated from the presence of experimental known polymorphs of benzocaine, the conformers generated at the lowest energy region can be considered as the possible polymorphs of benzocaine which are yet to be resolved. The Hirshfeld analysis and XRD patterns revealed the thermodynamic stability of the polymorph at lowest energy region along with the morphological studies exposed useful insight to the crystal morphology.

\section{Acknowledgement}

The authors were grateful to the DST-SERB for providing financial assistance to the research under the fast track scheme and Dr L S price for the support in DMACRYS usage. The authors also thankful to the garuda clustering service for the computational aid provided for the proper completion of this research .

\section{References}

1. K. Raza, P.Kumar, S. Ratan, R. Malik, S. Arora, SOJ Pharma Pharma Sci. 2014, 1(2), 10. https://doi.org/10.15226/2374-6866/1/1/00111

2. A. M. Reilly, R. I. Cooper, C. S. Adjiman, S. Bhattacharya, A. D. Boese, J. G. Brandenburg, P. J. Bygrave, R. Bylsma, J. E. Campbell, R. Car, D. H. Case, R. Chadha, J. C. Cole, K. Cosburn, H. M. Cuppen, F. Curtis, G. M. Day, R. A. DiStasio Jr, A. Dzyabchenko, B. P. van Eijck, D. M. Elking, J. A. van den Ende, J.C. Facelli, M.B. Ferraro, L. Fusti-Molnar, C.-A. Gatsiou, T.S. Gee, R. de Gelder, L.M. Ghiringhelli, H. Goto,
S. Grimme, R. Guo, D.W.M. Hofmann, J. Hoja, R.K. Hylton, L. Iuzzolino, W. Jankiewicz, D. T. de Jong, J. Kendrick, N. J. J. de Klerk, H.-Y. Ko, L. N. Kuleshova, X. Li, S. Lohani, F. J. J. Leusen, A. M. Lund, J. Lv, Y. Ma, N. Marom, A. E. Masunov, P. McCabe, D. P. McMahon, H. Meekes, M. P. Metz, A. J. Misquitta, S. Mohamed, B. Monserrat, R. J. Needs, M. A. Neumann, J. Nyman, S. Obata, H. Oberhofer, A. R. Oganov, A. M. Orendt, G. I. Pagola, C. C. Pantelides, C. J. Pickard, R. Podeszwa, L. S. Price, S. L. Price, A. Pulido, M. G. Read, K. Reuter, E. Schneider, C. Schober, G. P. Shields, P. Singh, I. J. Sugden, K. Szalewicz, C. R. Taylor, A. Tkatchenko, M .E. Tuckerman, F. Vacarro, M. Vasileiadis, A. Vazquez-Mayagoitia, L. Vogt, Y. Wang, R. E. Watson, G. A. de Wijs, J. Yang, Q. Zhu, C. R. Groom, Acta Crystallographica Section B, 2016, 72, 439-459.

https://doi.org/10.1107/S2052520616007447

3. B. K. Sinha, Vasantha pattabhi, proc indian acad sci (chem sci). 1987, 98, no3, 229-234.

4. D. E. Lynch and I. McClenaghan, Acta Crystallographica Section E 2002, 58, o708-o709. https://doi.org/10.1107/S1600536802009674

5. E. J. Chan, A. D. Rae and T. R. Welberry, Acta Crystallographica Section B 2009, 65, 509-515. https://doi.org/10.1107/S0108768109018898

6. M. J. Frisch, G. W. Trucks, H. B. Schlegel, G. E. Scuseria, M. A. Robb, J. R. Cheeseman, G. Scalmani, V. Barone, B. Mennucci, G. A. Petersson, H. Nakatsuji, M. Caricato, X. Li, H. P. Hratchian, A. F. Izmaylov, J. Bloino, G. Zheng, J. L. Sonnenberg, M. Hada, M. Ehara, K. Toyota, R. Fukuda, J. Hasegawa, M. Ishida, T. Nakajima, Y. Honda, O. Kitao, H. Nakai, T. Vreven, J. A. Montgomery Jr., J. E. Peralta, F. Ogliaro, M. J. Bearpark, J. Heyd, E. N. Brothers, K. N. Kudin, V. N. Staroverov, R. Kobayashi, J. Normand, K. Raghavachari, A. P. Rendell, J. C. Burant, S. S. Iyengar, J. Tomasi, M. Cossi, N. Rega, N. J. Millam, M. Klene, J. E. Knox, J. B. Cross, V. Bakken, C. Adamo, J. Jaramillo, R. Gomperts, R. E. Stratmann, O. Yazyev, A. J. Austin, R. Cammi, C. Pomelli, J. W. Ochterski, R. L. Martin, K. Morokuma, V. G. Zakrzewski, G. A. Voth, P. Salvador, J. J. Dannenberg, S. Dapprich, A. D. Daniels, Ö. Farkas, J. B. Foresman, J. V. Ortiz, J. Cioslowski and D. J. Fox, Gaussian, Inc., Wallingford, CT, USA, 2009.

7. J. R. Holden, Z. Du, H. L. Ammon, Journal of Computational Chemistry. 1993, 14, 422-437. https://doi.org/10.1002/jcc.540140406

8. P. G. Karamertzanis and C. C. Pantelides, Journal of Computational Chemistry 2005, 26, 304-324. https://doi.org/10.1002/jcc.20165

9. W. R.Busing, Report ORNL-5747. Oak Ridge National Laboratory, Oak Ridge 1981.

10. S. M. Prasad, Z. Du, N. Albu, H. L. Ammon, University of Maryland, College Park MD 2004

11. J. P. Perdew, Physical Review B 1986, 33, 8822-8824. https://doi.org/10.1103/PhysRevB.33.8822

12. C. Lee, W. Yang and R. G. Parr, Physical Review B 1988, 37, 785-789. https://doi.org/10.1103/PhysRevB.37.785 
13. S. L. Price, M. Leslie, G. W. A. Welch, M. Habgood, L. S. Price, P. G. Karamertzanis and G. M. Day, Physical Chemistry Chemical Physics 2010, 12, 8478-8490. https://doi.org/10.1039/c004164e

14. A. J stone, GDMA University of Cambridge, UK, 1999.

15. D. E. Williams and S. R. Cox, Acta Crystallographica Section B 1984, 40, 404-417. https://doi.org/10.1107/S010876818400238X

16. D. S. Coombes, S. L. Price, D. J. Willock and M. Leslie, The Journal of Physical Chemistry 1996, 100, 7352-7360. https://doi.org/10.1021/jp960333b

17. M. Born, Mathematical Proceedings of the Cambridge Philosophical Society 1940, 36, 160-172. https://doi.org/10.1017/S0305004100017138

18. J. A. Chisholm and S. Motherwell, Journal of Applied Crystallography 2005, 38, 228-231. https://doi.org/10.1107/S0021889804027074

19. S. L. Price, Chemical Society Reviews 2014, 43, 2098- 2111. https://doi.org/10.1039/C3CS60279F
20. M. A. Spackman and J. J. McKinnon, CrystEngComm 2002, 4, 378-392. https://doi.org/10.1039/B203191B

21. G. Wang, S. Schönecker, S. Hertzman, Q.-M. Hu, B. Johansson, S. K. Kwon and L. Vitos, Physical Review B 2015, 91, 224203. https://doi.org/10.1103/PhysRevB.91.224203

22. A. T. Anghel, G. M. Day and S. L. Price, CrystEngComm 2002, 4, 348-355. https://doi.org/10.1039/B202084J

23. T. Beyer, G. M. Day, and S. L. Price J. Am. Chem. Soc. 2001, 123, 5086-5094 https://doi.org/10.1021/ja0102787

24. A. Bravais Etudes Crystallographiques Paris: Academic des Sciences: 1913.

25. G .Freidal Bull Soc Fr Miner, 1907, 30, 326.

26. J. D. H. Donnay, D. Harker, Am Miner, 1937, 22, 463.

27. D. S. Coombes, C. R. A. Catlow, J. D. Gale, M. J. Hardy and M. R. Saunders, Journal of Pharmaceutical Sciences 2002, 91, 1652-1658. https://doi.org/10.1002/jps.10148

\section{Povzetek}

Za izračune termodinamsko stabilnih kristalnih struktur polimorfov benzokaina smo uporabili ab intio metode. Za začetno optimizacijo spojine $\mathrm{v}$ plinskem stanju in fleksibilnim torzijskim kotom smo uporabili MP2 metodo in bazni set 6-31G(d,p). S kvantnokemijskimi izračuni smo z iskanjem lokalnih minimumov iskali morebitne stabilne konformere. Tako izračunane morebitne stabilne konformere smo izbrali in z nadaljnjo mrežno minimizacijo preverjali njihovo stabilnost. Stabilnost in karakteristike izračunanih struktur smo analizirali tudi s primerjavo izračunanih vodikovih vezi in primerjavo le-teh z eksperimentalno določenimi podatki. Z morfološkimi študijami molecule benzokaina v globalnem minimum smo želeli najti morfološko pomembne mreže. 